\title{
ARTICLES
}

\section{Focal Adhesion Kinase Is a Key Mediator of Human Trophoblast Development}

\author{
Daniel James MacPhee, Homa Mostachfi, Robin Han, Stephen James Lye, \\ Martin Post, and Isabella Caniggia
}

Program in Development and Fetal Health, Samuel Lunenfeld Research Institute, Program in Lung Biology, Department of Obstetrics and Gynecology and Physiology, University of Toronto, Mt. Sinai Hospital, Hospital for Sick Children, Toronto, Ontario, Canada

\begin{abstract}
SUMMARY: Trophoblast differentiation during the first trimester of pregnancy involves cell proliferation and invasion and extracellular matrix (ECM) remodeling. Reports have indicated that, in a variety of cell types, processes such as proliferation, invasion, and ECM remodeling require the turnover of focal adhesions mediated by a cytoplasmic tyrosine kinase named focal adhesion kinase (FAK). Therefore, in the present study we examined the expression and spatial localization of FAK during early human placental development. Immunocytochemical and immunoblot analysis showed that FAK and a focal adhesionassociated protein named paxillin were highly expressed between the 5th and 8th weeks of gestation, specifically in villous cytotrophoblast and extravillous trophoblast (EVT) cells. Activated FAK, phosphorylated on Tyr-397, colocalized with $\alpha 5$ integrin and matrix metalloproteinase-2 (MMP2) expression in EVT cells within a previously characterized intermediate, invasiverestrained region. FAK and paxillin expression dramatically decreased after 10 to 12 weeks of gestation coincident with increasing $\mathrm{pO}_{2}$ levels. Exposure of human villous explants of 5 to 8 weeks to a $3 \% \mathrm{O}_{2}$ environment resulted in increased trophoblast outgrowth, cell proliferation, and detection of $\alpha 5$ integrin and MMP2, as well as increased activation of FAK in EVT cells compared with explants grown in a $20 \% \mathrm{O}_{2}$ environment. To determine whether FAK was a key requisite for trophoblast differentiation, villous explants of 5 weeks gestation were grown in Matrigel in a $3 \% \mathrm{O}_{2}$ environment and incubated with 20-mer antisense FAK oligonucleotides. A dramatic reduction of trophoblast outgrowth was observed in antisense-treated explants compared with missense and control cultures, and, in addition, cell proliferation and MMP2 activity in antisense-treated explants were dramatically reduced. These data suggest that FAK is a key kinase involved in early trophoblast cell differentiation and plays a role in regulating cell proliferation and motility during early placental development. (Lab Invest 2001, 81:1469-1483).
\end{abstract}

$D$ espite years of research, the molecular basis of placental development is still poorly understood. As a result, an understanding of the etiologic basis of diseases during pregnancy, such as preeclampsia, remains obscure. The human placenta represents a fetal-maternal interaction that is essential for a successful pregnancy (Caniggia et al, 2000b). It consists of branching chorionic villi with outer syncytiotrophoblast cells, underlying cytotrophoblast cells, and a stroma. Cytotrophoblast cells are found in chorionic villi of two types, floating and anchoring villi. Floating villi make up the majority of chorionic villi and are bathed in maternal blood, facilitating gas and nutrient exchange for the developing fetus. During early placen-

\section{Received August 17, 2001}

This work was supported by the Department of Obstetrics and Gynecology and the Medical Research Council of Canada, Grant MT-14096 (to IC). Address reprint requests to: Program in Development and Fetal Health SLRI, Department of Obstetrics and Gynecology and Physiology, University of Toronto, Mt. Sinai Hospital, 600 University Avenue, Toronto, Ontario, Canada, M5G 1X5.E-mail: Caniggia@mshri.on.ca tation, cytotrophoblast cells in floating villi proliferate and differentiate by fusing to form a multinucleated syncytiotrophoblast layer. In contrast, cytotrophoblast cells in anchoring villi either fuse to form the syncytiotrophoblast layer or break through the syncytium to form columns of extravillous trophoblast (EVT) cells that connect the embryo to the uterine wall. The formation of anchoring villi is accompanied by changes in the synthesis and degradation of extracellular matrix (ECM) proteins, the spatial distribution of ECM proteins, and the expression of adhesion molecules (Damsky et al, 1992).

During early placental development, trophoblast cells are exposed to a low-oxygen environment because of restricted maternal arterial connections with the intervillous space (Burton et al, 1999; Jauniaux et al, 2000; Rodesch et al, 1992). Recent reports have indicated that a switch in oxygen tension can modulate trophoblast differentiation along the invasive pathway and that low oxygen tension can specifically maintain trophoblast cells in a proliferative, noninvasive intermediate phenotype characteristic of early placental development (Genbacev et al, 1996, 1997). 
We have recently reported that markers associated with this trophoblast intermediate phenotype, such as proliferation, fibronectin synthesis, $\alpha 5$ integrin expression, and matrix metalloproteinase-2 (MMP2) activity, are all elevated in a low-oxygen environment (Caniggia et al, 2000a). In addition, expression of hypoxiainducible factor- $1 \alpha$ (HIF-1 $\alpha$ ), a basic helix-loop-helixper arnt sim (PAS) domain transcription factor that binds and activates genes that regulate adaptation to low oxygen (Wang et al, 1995), is elevated during the same time period and appears to be critical for mediating the biological effects of oxygen on early trophoblast differentiation through transforming growth factor- $\beta_{3}\left(\right.$ TGF- $\beta_{3}$ ) (Caniggia et al, 2000a).

Trophoblast invasion into the uterine wall, like proliferation, is also spatially and temporally regulated (Cross et al, 1994). The invasive activity of the trophoblast cells is at a maximum during the first trimester of gestation, peaking at approximately 10 to 12 weeks. In anchoring villi, EVT cells within the proximal site of the column proliferate, whereas EVT cells within the distal site of the column differentiate along an invasive pathway. These cells ultimately invade the decidua, the first third of the myometrium and proximal regions of uterine spiral arterioles. During this transition of trophoblast cells from a proliferative to an invasive state, there is considerable trophoblast cell-ECM remodeling marked by specific integrin switching (from expression of $\alpha 6 \beta 4$ to $\alpha 5 \beta 1$ and $\alpha 1 \beta 1$ ) as well as the secretion of matrix metalloproteinase-9 (Bischof et al, 1993; Damsky et al, 1992; Librach et al, 1991).

Remodeling of cell-ECM contacts uses focal adhesion kinase (FAK)-mediated tyrosine phosphorylation (llic et al, 1995; MacPhee and Lye, 2000; Schlaepfer et al, 1999). Focal adhesions are comprised of clusters of membrane integrins bound on the extracellular domain to the ECM and on their cytoplasmic domain to the protein tyrosine kinase, FAK (Schlaepfer and Hunter, 1998). Other proteins kinases such as c-Src, phosphatidylinositol 3-kinase, and various adapter proteins, such as paxillin and vinculin, subsequently bind to FAK, making it a key signal transducer of "outside:inside" signaling (Hanks and Polte, 1997; Juliano, 1996; Richardson and Parsons, 1995; Schlaepfer et al, 1999). FAK plays a key role in regulating cytoskeletal organization, gene expression, and cell behavior such as cell spreading and migration (Hanks and Polte, 1997). In addition, FAK may also have a role in regulating the $\mathrm{G} 1$ to $S$ phase transition of the cell cycle (Reiske et al, 2000; Zhao et al, 1998) and the suppression of anoikis (Frisch et al, 1996; Hungerford et al, 1996; Ruoslahti and Reed, 1994; Xu et al, 1996).

Because FAK expression and activity appear to play key roles in cell proliferation, survival, and migration, we examined the expression, localization, and activation state of FAK during human placental development. Our data indicate that FAK is a key kinase that mediates the cellular events involved in human trophoblast development.

\section{Results}

\section{Expression and Spatial Localization of FAK and Paxillin during Pregnancy}

Immunoblot analysis showed that FAK was highly detectable between the 5th and 8th weeks of gestation and markedly decreased thereafter (Fig. 1A). Immunoprecipitation of FAK and subsequent immunoblotting with an antibody directed against phosphotyrosines (PY99) demonstrated that the phosphotyrosine content of FAK, indicative of its activation, correlated with its expression pattern (Fig. 1B). Phosphotyrosine content decreased markedly following 10 to 12 weeks of gestation. Because paxillin associates with FAK in focal adhesions and is a downstream substrate for FAK-Src-family protein tyrosine kinase complexes (Schlaepfer et al, 1999), we analyzed the expression of paxillin on immunoblots. Paxillin was also highly expressed between the 5th and 8th weeks of gestation and then markedly decreased (Fig. 1C). In addition, paxillin co-immunoprecipitated with FAK immunoprecipitates when both FAK and paxillin were highly expressed at 5 to 8 weeks of gestation (data not shown).

To determine the spatial localization of FAK and paxillin in human placentae during gestation, we analyzed sections of placental tissue via immunocytochemistry using FAK and paxillin-specific antisera. In floating villi of 5 to 8 weeks gestation, FAK and paxillin were localized to villous syncytiotrophoblast and cytotrophoblast cells of chorionic villi and then significantly decreased in expression following 10 to 12 weeks of development (Fig. 2). FAK and paxillin staining was cytoplasmic and membrane-specific. In anchoring villi of 5 to 8 weeks, FAK and paxillin were also localized to villous cytotrophoblast cells, and in a limited extent to syncytiotrophoblast cells, but were also highly detectable in membrane-specific regions of extravillous trophoblast cells (Fig. 3). Following 10 to 12 weeks of gestation, FAK and paxillin expression in syncytiotrophoblast, cytotrophoblast, and extravillous trophoblast cells within the proximal columns decreased significantly and became restricted to distal trophoblast cells invading the decidua (Fig. 3).

\section{Expression of Activated FAK during Early Placental Development}

Activated FAK expression and its spatial localization were measured with an antibody that specifically recognizes FAK when autophosphorylated on Tyr397. Between 4 to 8 weeks of gestation, activated FAK was localized in proliferative extravillous trophoblast cells that also coexpressed $\alpha 5$ integrin and MMP2 (Fig. 4). Following 10 to 12 weeks gestation, analogously to FAK expression in general (Fig. 3), activated FAK expression decreased markedly in association with decreased $\alpha 5$ integrin and MMP2 expression but in contrast to the continuous detection of proliferation in extravillous trophoblast cells (Fig. 4). 


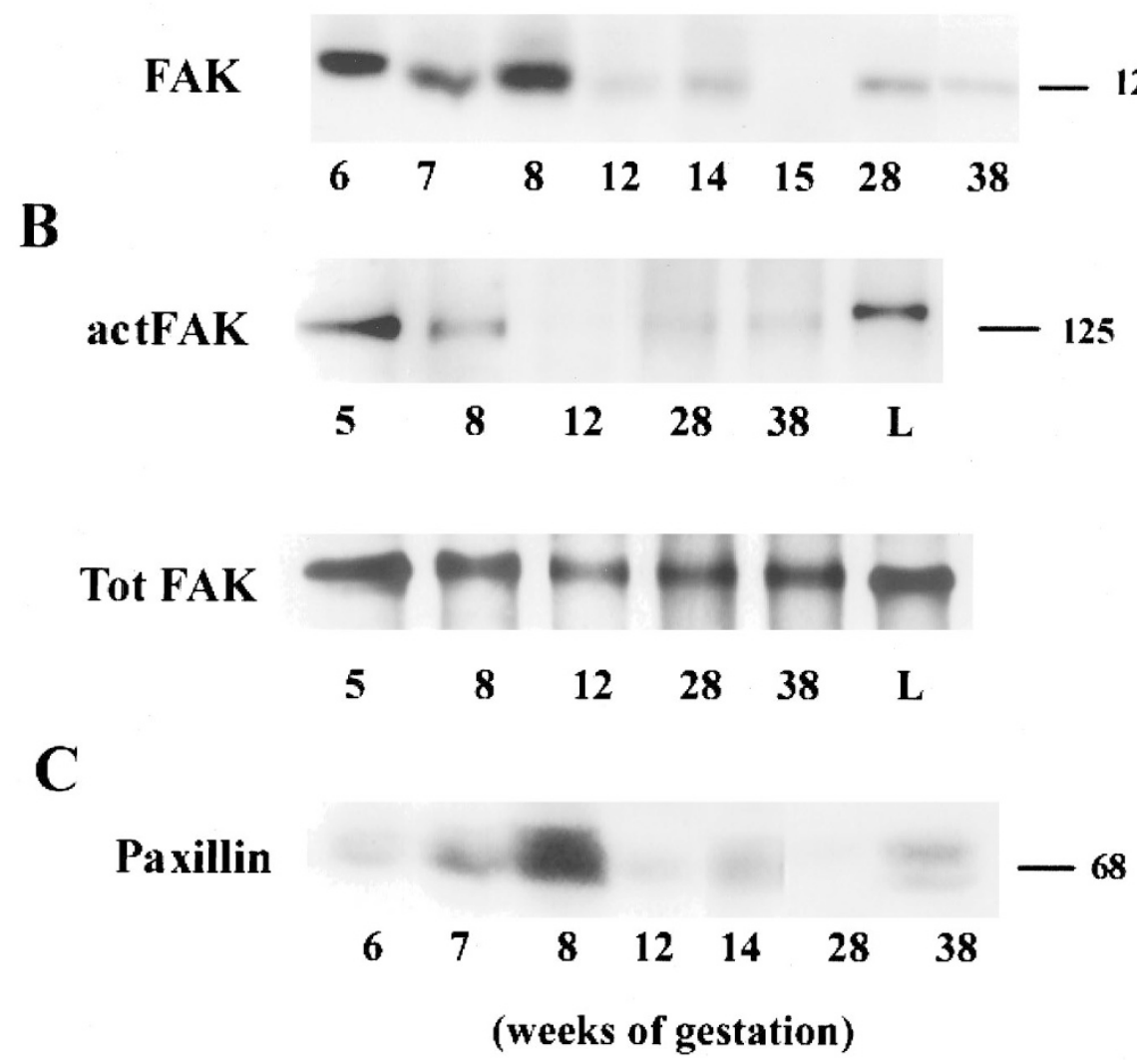

Figure 1.

Immunoblot analysis of focal adhesion kinase (FAK; A), tyrosine phosphorylated FAK (actFAK; B), and paxillin expression (C) in placental lysates during human gestation. Both FAK and paxillin expression were markedly higher between 5 to 8 weeks of gestation and markedly decreased thereafter. Immunoprecipitated FAK (B, upper blot) was analyzed for phosphotyrosine levels using phosphotyrosine-specific antisera. Tyrosine phosphorylated FAK was highly detectable at 5 and 8 weeks of gestation and decreased significantly thereafter. Total immunoprecipitated FAK (Tot FAK) was detectable in all samples analyzed (B; lower blot). Numbers on the right side of each blot represent relative molecular mass $\left(\mathrm{M}_{\mathrm{r}}\right)$. L, liver lysate positive control.

\section{Effect of Oxygen Tension on FAK Expression}

Oxygen tension has been shown to be a key regulator of early events of trophoblast differentiation. Therefore, we determined the effect of different oxygen tensions on FAK expression and activity in villous explant cultures of 5 to 8 weeks. Villous explants cultured under a $20 \% \mathrm{O}_{2}$ environment exhibited limited outgrowth and barely detectable FAK activation in extravillous trophoblast cells (Fig. 5, right panels). Cell proliferation and MMP2 expression in these cells was also minimal (Fig. 5, right panels). In contrast, explants cultured in a $3 \% \mathrm{O}_{2}$ environment exhibited highly proliferative extravillous trophoblast cell outgrowth, significant MMP2 expression and intense FAK activation that correlated with $\alpha 5$ integrin expression (Fig. 5, left panels).

\section{Antisense Targeting of FAK in Villous Explants}

Because FAK was highly expressed and activated during early placental development and is also regulated by low oxygen, we hypothesized that FAK may be a key mediator of trophoblast differentiation during this period of gestation. To determine the role of FAK in the differentiation process, we used antisense phosphorothioate oligonucleotides to FAK to inhibit FAK expression. Control villous explants of 5 to 8 weeks gestation were cultured at $3 \% \mathrm{O}_{2}$ in DMEM/F12 in the absence of oligonucleotides or in the presence of missense oligonucleotides $(10 \mu \mathrm{M})$. Explants exhibited the typical low-oxygen tension-induced outgrowth (Fig. 6A, left and middle panels). In contrast, villous explants incubated at $3 \% \mathrm{O}_{2}$ with $10 \mu \mathrm{m}$ antisense FAK oligonucleotides showed markedly impaired trophoblast outgrowth (Fig. 6A, right panel). FAK expression was markedly decreased in the antisense-treated explants, compared with media and missense controls (Fig. 6B, upper panels), but paxillin was still highly expressed in these explants (Fig. 6B, lower panels), demonstrating the specificity and nontoxicity of the antisense targeting strategy, because paxillin can exist at focal adhesion sites independently of FAK (Liu et al, 1999). Extravillous trophoblast cells in control explants were actively proliferating as determined by Ki67 antigen detection. However, tropho- 
FAK
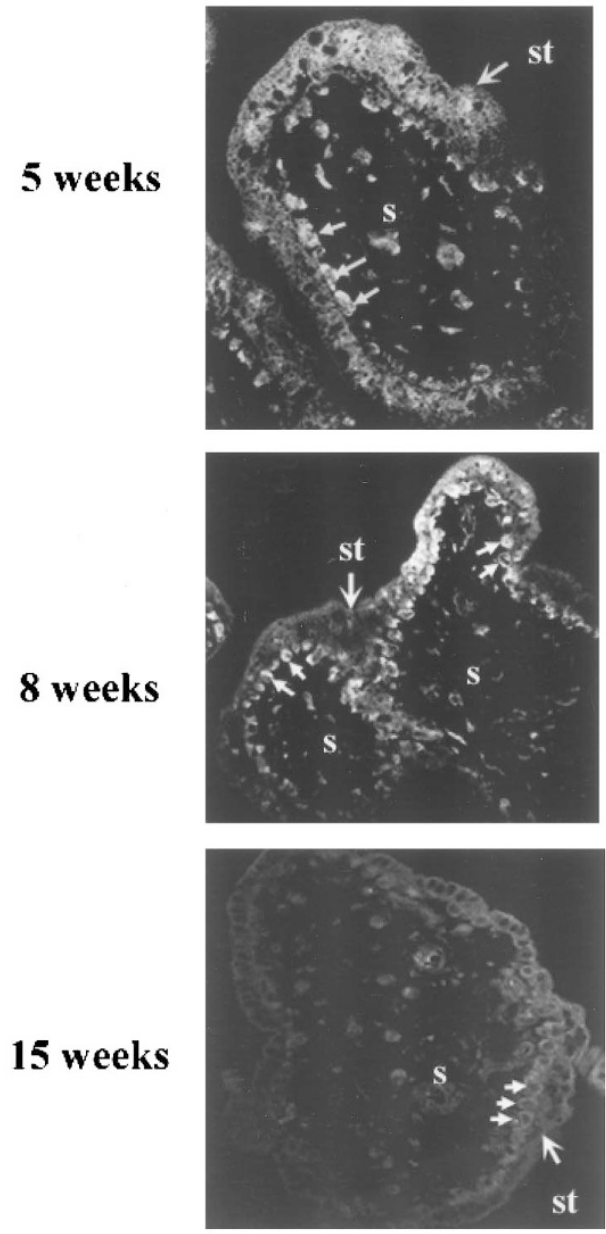

st

\section{Control}

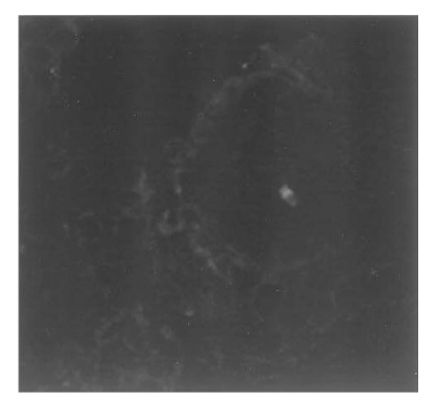

PAXILLIN
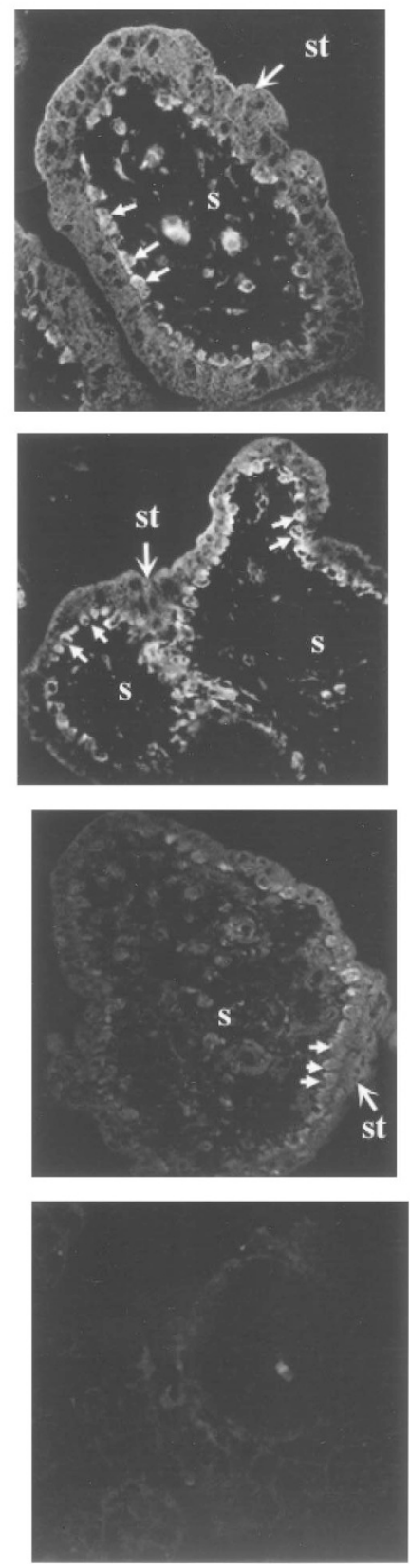

\section{Figure 2.}

Immunolocalization of FAK and paxillin in floating villi from 5, 8, and 15 weeks gestation. FAK and paxillin were detected in syncytiotrophoblast cells (st) but at low levels. However, FAK and paxillin were highly expressed in villous stem cytotrophoblast cells (small arrows) between 5 and 8 weeks. At 15 weeks of gestation, FAK and paxillin expression in both syncytiotrophoblast and cytotrophoblast cells was markedly decreased. Control panels contain sections of floating villi from 8 weeks gestation that were incubated with only the appropriate fluorescently conjugated secondary antisera. s, stroma. Scale bar $=50 \mu \mathrm{m}$.

blasts cells from antisense-treated explants exhibited markedly low levels of cell proliferation (Fig. 7A, Table 1). Using a terminal deoxynucleotidyl transferasedUTP-nick end labeling (TUNEL) assay, we then examined whether the antisense phenotype was due to perturbations in cell proliferation or increased apoptosis. In contrast to syncytiotrophoblast cells, extravillous trophoblast cells in both control and antisensetreated explants did not exhibit any significant positive TUNEL reaction, suggesting that the observed antisense phenotype was not due to apoptosis (Fig. 7B).
Culture media from all experimental groups was also collected and analyzed, in triplicate, for MMP2 activity by gel zymography. Significantly lower MMP2 activity was detected in media from antisense-treated explants compared with media from control explants (Fig. 7C).

\section{Discussion}

Damsky et al (1994) have indicated that the differentiation and net invasiveness of trophoblast cells during early placental development is determined, at least in 
FAK

5 weeks

8 weeks

12 weeks

15 weeks
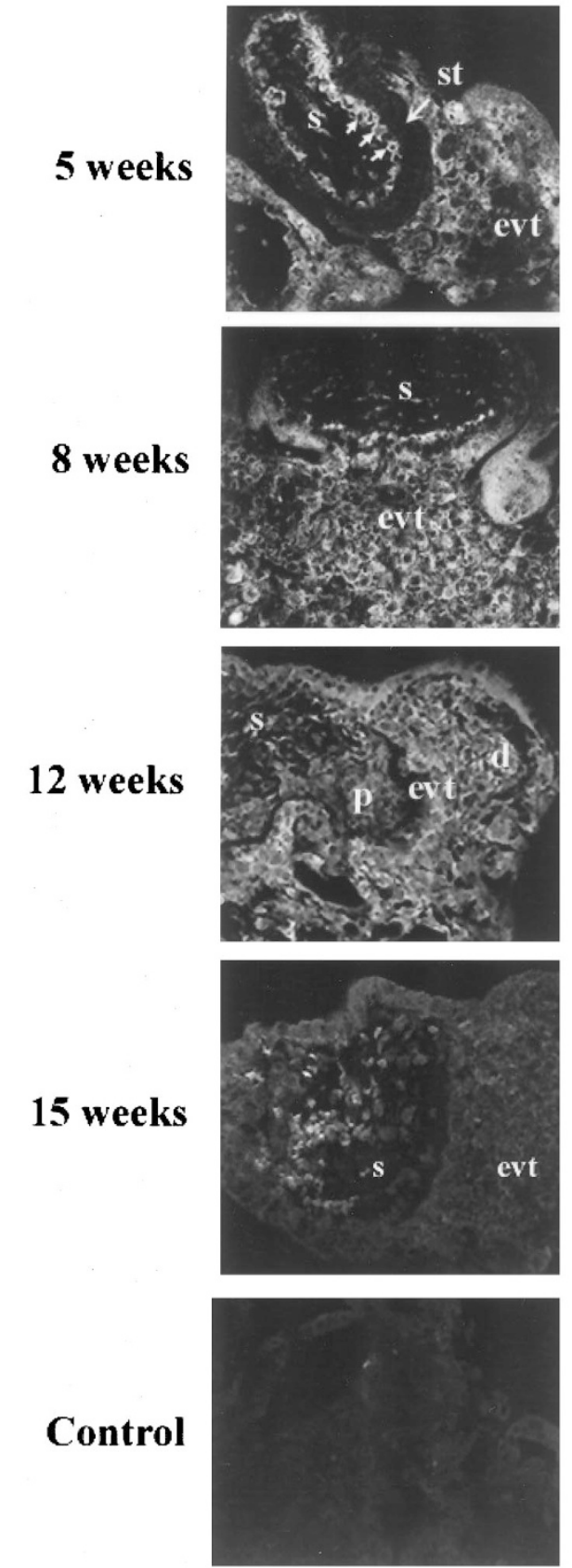

PAXILLIN
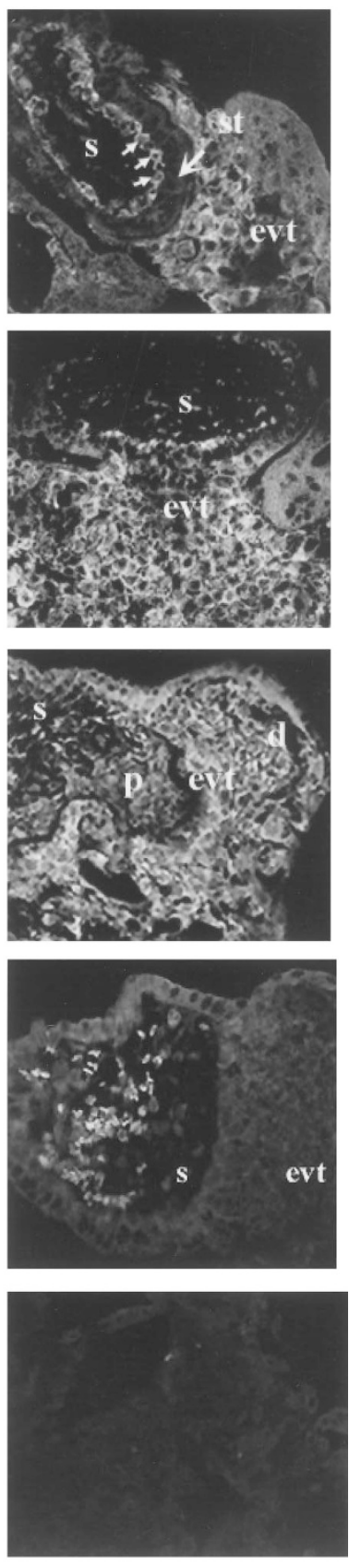

\section{Figure 3.}

Immunolocalization of FAK and paxillin in anchoring villi from 5, 8, 12, and 15 weeks gestation. Between 5 and 8 weeks of gestation, FAK and paxillin were localized to villous stem cytotrophoblast cells (small arrows) and to extravillous trophoblast cells (evt) within the proximal part of the invading column. There was also some limited detection of FAK and paxillin in syncytiotrophoblast cells $(s t)$. Note that at 12 weeks of gestation, FAK and paxillin expression decreased in extravillous trophoblast cells forming the proximal part of the column $(p)$ and was present in the extravillous trophoblast cells within the distal part of the column (d). At 15 weeks gestation, FAK and paxillin expression were significantly decreased in all regions except the stroma $(s)$. Control panels contain sections of anchoring villi, from 8 weeks gestation, that were incubated with only the appropriate fluorescently conjugated secondary antisera. Scale bar $=50 \mu \mathrm{m}$.

part, by regulation of integrin-mediated adhesion mechanisms that accelerate or restrain invasion. The cytoplasmic tyrosine kinase FAK has been demonstrated to be a mediator of integrin-mediated signaling (Boudreau and Jones, 1999). FAK initiates signaling pathways from focal adhesions to the nucleus that then regulate anchorage-dependent behavior such as proliferation, migration, and the suppression of anoikis (Gilmore and Romer, 1996; Richardson and Parsons, 1995; Schlaepfer et al, 1999). Therefore, we hypothesized that FAK was a potentially important kinase for placental development. Our data is the first to dem- 


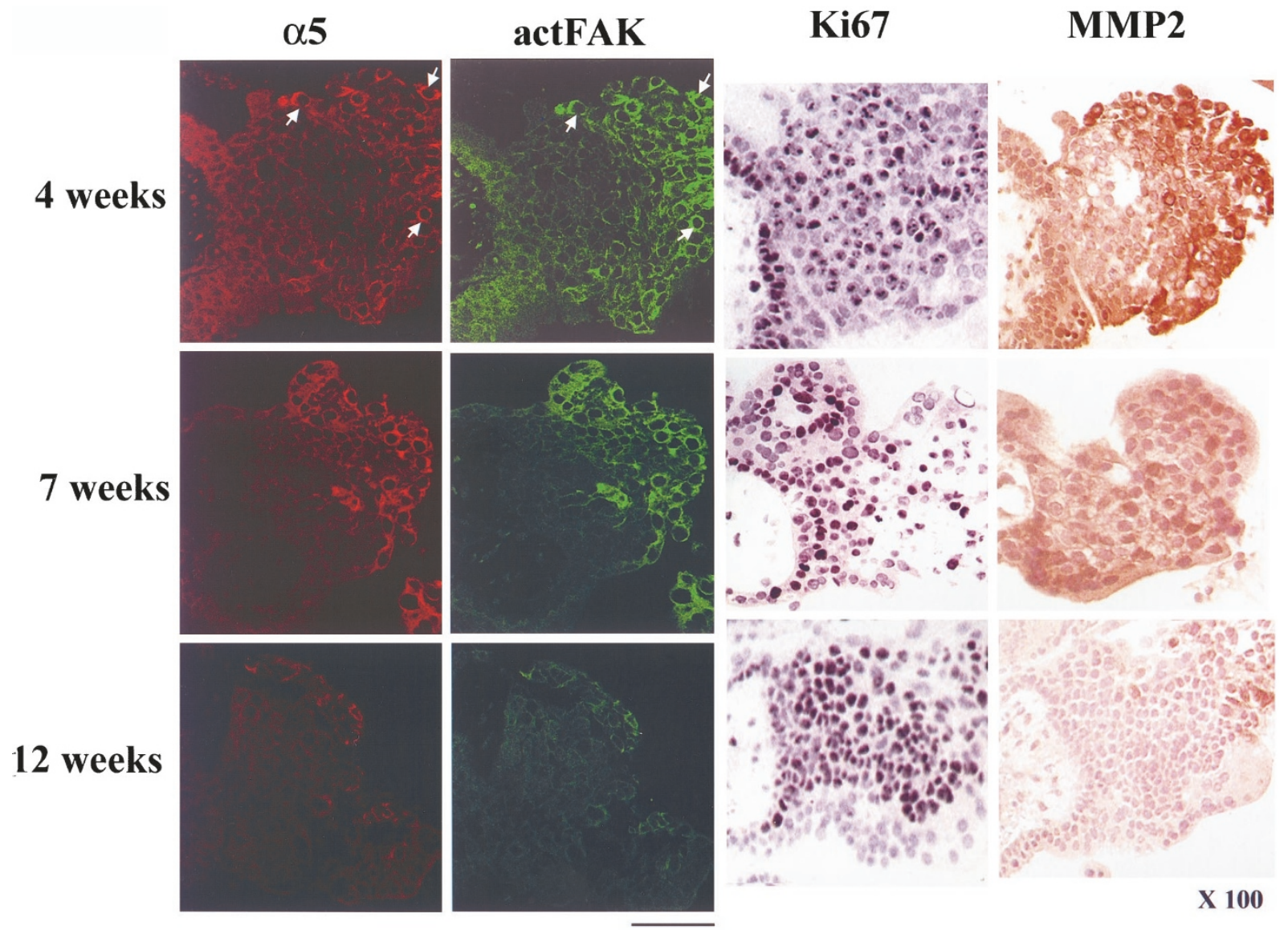

Figure 4.

Immunodetection of $\alpha 5$ integrin, activated FAK (actFAK), Ki67 antigen, and matrix metalloproteinase-2 (MMP2) in human anchoring villi. At 4 to 7 weeks of gestation, $\alpha 5$ integrin and FAK colocalized in extravillous trophoblast cells (arrows) in a transitional region that was highly proliferative. At 4 to 7 weeks of gestation, strong positive immunoreactivity for MMP2 was also found in extravillous trophoblast (EVT) cells within the column. By 12 weeks of gestation, $\alpha 5$ integrin, FAK and MMP2 expression were markedly reduced in EVT cells. Scale bar $=50 \mu \mathrm{m}$. Immunoperoxidase staining, $\times 100$.

onstrate that FAK is a key mediator of trophoblast proliferation, motility, and differentiation during early pregnancy.

\section{Expression and Spatial Localization of FAK and Paxillin}

FAK and paxillin proteins were highly expressed between 5 to 8 weeks of gestation and especially localized to both villous stem cytotrophoblast cells and extravillous trophoblast cells. Analysis of immunoprecipitated FAK for phosphotyrosine content demonstrated that a proportion of FAK during this period of early placental gestation was in an "activated" kinase state. These data demonstrate that FAK is expressed and active in developing trophoblast cells at a time when these cells are highly proliferative and migratory. Parast et al (2001) has also recently reported that FAK is highly activated in motile rat choriocarcinoma cells during differentiation into trophoblast giant cells. FAK is known to enhance cell migration through focal adhesion turnover because fibroblasts from FAKdeficient mice exhibit markedly reduced cell migration and large focal adhesions (llic et al, 1995). However, cell proliferation defects in these null fibroblasts were masked because a mutation in the cell-cycle regula- tor, p53, was introduced into FAK null cells to enhance their proliferation (Gilmore and Romer, 1996; Tsukuda et al, 1993). Gilmore and Romer (1996) and Richardson et al (1997) have also found that overexpression of the C-terminus of FAK as a negative inhibitor of FAK function, in endothelial cells or chicken embryo cells, respectively, reduces cell migration and proliferation.

\section{Activated FAK and Extravillous Trophoblast Differentiation}

To address more specifically the spatial localization of activated FAK, we used an antiserum raised against autophosphorylated FAK (Tyr-397) for immunocytochemical experiments. Phosphorylation of the FAK activation loop is largely dependent on the FAK autophosphorylation site, although the phosphorylation of both the activation loop and autophosphorylation sites makes up the integrin-stimulated FAK signaling response (Ruest et al, 2000).

Between the 5th and 8th weeks of human gestation, activated FAK was specifically localized to extravillous trophoblast cells of the developing column in anchoring villi, and activated FAK expression colocalized with $\alpha 5$ integrin expression. Integrin switching has been 

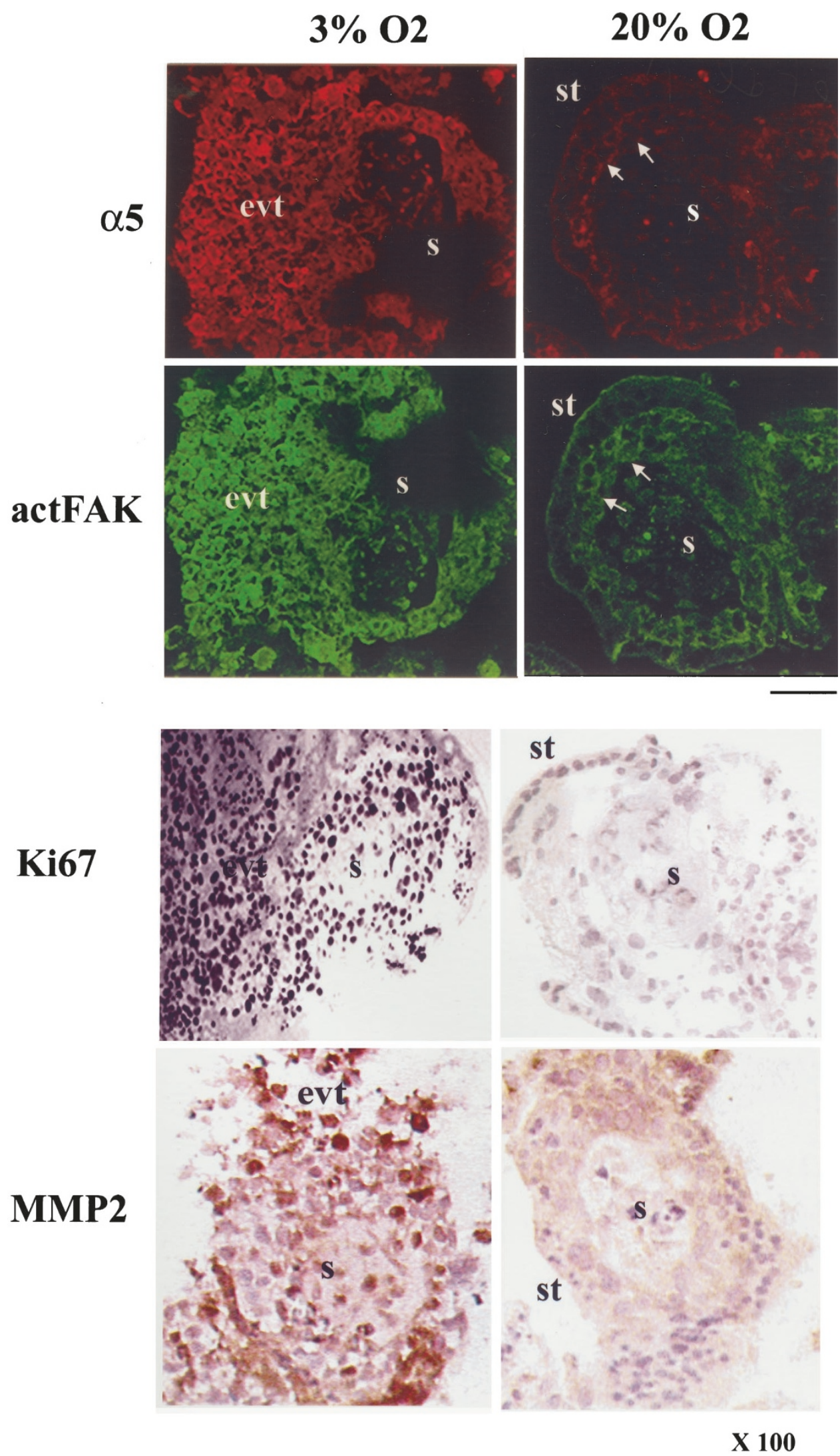

Figure 5.

Oxygen tension regulates placental development. Explants of 5 to 8 weeks gestation cultured in a $3 \% \mathrm{O}_{2}$ showed increased EVT outgrowth and exhibited higher cell proliferation and expression of $\alpha 5$ integrin, activated FAK (actFAK), and MMP2 than explants cultured in a $20 \% \mathrm{O}_{2}$. Scale bar $=50 \mu \mathrm{m}$. Immunoperoxidase staining, $\times 100$. 

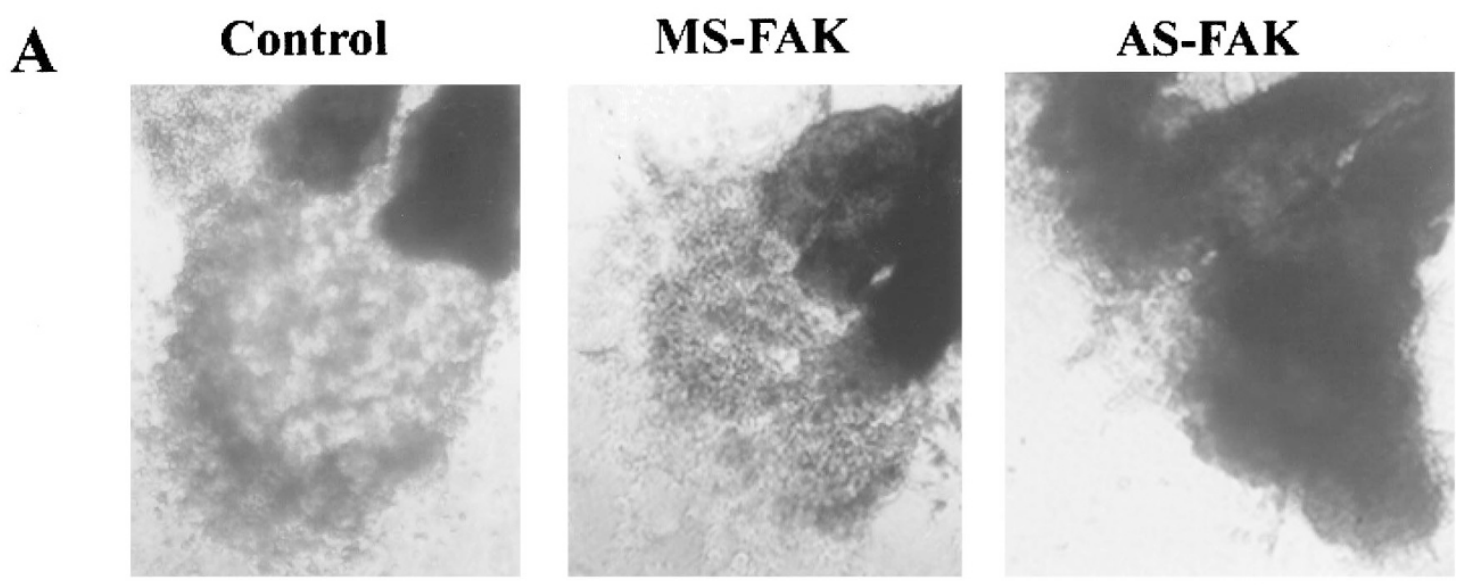

$\mathbf{X} 50$
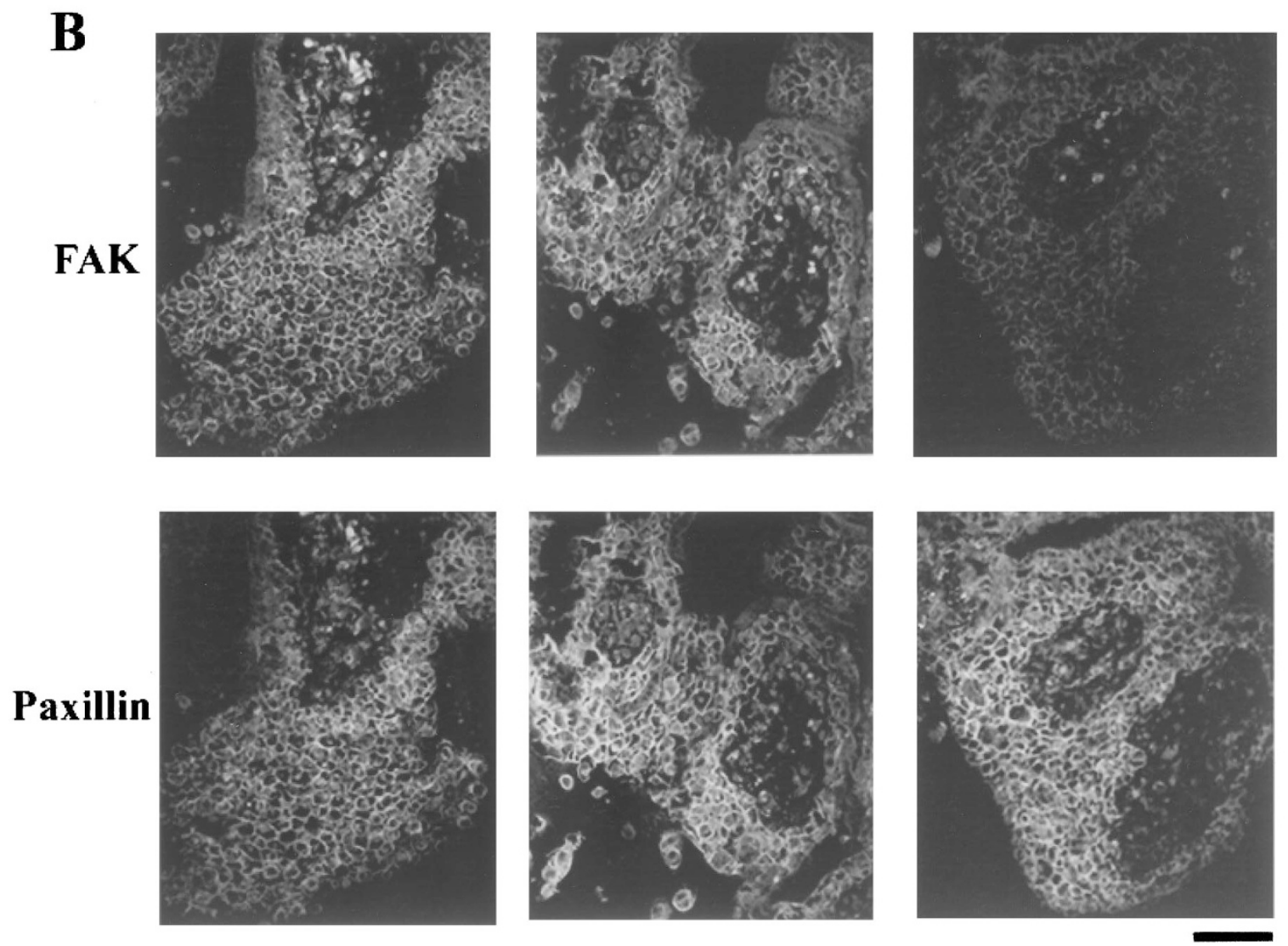

\section{Figure 6.}

Antisense targeting of FAK inhibits trophoblast outgrowth. A, Human villous explants of 5 weeks gestation cultured in a $3 \% \mathrm{O}_{2}$ environment were incubated in media alone (Control) or media containing missense (MS-FAK) or antisense (AS-FAK) FAK phosphorothioate oligonucleotides. Antisense FAK oligonucleotides markedly reduced extravillous trophoblast outgrowth compared with control and missense-treated explants. B, FAK expression in antisense-treated explants was significantly reduced compared with control and missense-treated explants, whereas paxillin expression was unchanged in all treatment groups. Scale bar $=50 \mu \mathrm{m}$.

described during trophoblast differentiation (Bischof et al, 1993; Damsky et al, 1992). Damsky et al (1994) have suggested that colocalization of $\alpha 5$ integrin with $\beta 1$ (as a fibronectin receptor) in extravillous trophoblast cells correlates with the adoption of an intermediate, proliferative, and migratory, yet invasionrestrained phenotype. This phenotype occurs at a time when $\mathrm{pO}_{2}$ levels in the intervillous space are low (Genbacev et al, 1997; Rodesch et al, 1992), and we hypothesize that FAK may mediate the differentiation of the invasion-restrained phenotype within extravillous trophoblast cells during this time.

\section{The Effect of Oxygen Tension on FAK Expression}

Oxygen tension is a critical regulator of trophoblast differentiation (Caniggia et al, 2000b; Genbacev et al, 1996, 1997), and oxygen-mediated early events of 
trophoblast differentiation are, in part, mediated by TGF $\beta 3$ through HIF- $1 \alpha$ transcription factors (Caniggia et al, 2000a). In a low-oxygen-tension environment, before 10 to 12 weeks of gestation, trophoblast cells proceed through the initial stages of their normal differentiation by up-regulating DNA synthesis, HIF$1 \alpha, \alpha 6 \beta 4$, and $\alpha 5 \beta 1$ integrins, fibronectin, and the metalloproteinase MMP2 (Caniggia et al, 1997a, 1997b; 2000a; Damsky et al, 1992, 1994). It is the distal stage of the differentiation process, when cytotrophoblasts become highly invasive and upregulate $\alpha 1 \beta 1$, that is inhibited under hypoxia (Caniggia et al, 2000b; Genbacev et al, 1996). This distal stage of differentiation is coincident with increased perfusion of the intervillous space with maternal blood at approximately 10 to 12 weeks of gestation and beyond (Burton et al, 1999; Rodesch et al, 1992).

Villous explants cultured in a $3 \% \mathrm{O}_{2}$ environment exhibited highly proliferative extravillous trophoblast cell outgrowth compared with villous explants isolated from the same placenta but cultured in a $20 \%$ environment. In addition, $3 \% \mathrm{O}_{2}$-cultured extravillous trophoblast cells stained intensely for activated FAK, $\alpha 5$ integrin, and MMP2 compared with cells cultured in a $20 \% \mathrm{O}_{2}$ environment. Increased activated FAK and $\alpha 5$ integrin expression were also observed when villous explants, cultured at $20 \% \mathrm{O}_{2}$, were incubated in conditions that mimic hypoxia, such as with either cobalt chloride or the iron chelator desferoxamine (data not shown). Therefore, FAK expression and activity are positively influenced by low-oxygen tension during early placental development, further suggesting a role for FAK as a mediator of early trophoblast differentiation before increased perfusion of the intervillous space. In support of this data, Seko et al (1999) has confirmed that hypoxia induces FAK activation and subcellular translocation of FAK to focal adhesions.

\section{FAK is a Key Mediator of Trophoblast Proliferation and Motility}

Because FAK was highly expressed and activated during early placental development, we used antisense oligonucleotides to FAK and a villous explant system to directly determine the role of FAK during trophoblast differentiation. Antisense-treated explants exhibited markedly reduced outgrowth compared with media and missense controls, suggesting that EVT migration and proliferation are altered. FAK's role in regulating cell migration has been well documented (Cary et al, 1996; Owen et al, 1999; Parsons et al, 2000). Recently, Taylor et al (2001) also reported that expression of an endogenous inhibitor of FAK, termed focal adhesion related nonkinase (FRNK), in vascular smooth muscle cells dramatically reduced cell migration. In addition, FAK null mice are embryonic lethal at embryonic day (E) 8.5 because of migration defects during gastrulation (llic et al, 1995). Examination of FAK null mice placentae has not been reported; therefore, it is currently unknown whether FAK is essential for early placental development.
Antisense-treated explants also exhibited significantly lower proliferation compared with control explants, and TUNEL assays indicated that the observed phenotype was not likely due to an increased incidence of apoptosis but to cell cycle arrest. Zhao et al (1998) showed that over-expression of wild-type FAK in National Institutes of Health (NIH) 3T3 cells accelerated $\mathrm{G} 1$ to $\mathrm{S}$ phase transition, and over-expression of a dominant negative FAK, lacking the terminal 14 amino acids, arrested cell-cycle progression at the $\mathrm{G} 1$ phase. Taylor et al (2001) also showed that, in addition to reducing migration, FRNK significantly decreased cell proliferation in vascular smooth muscle cells.

Our data from antisense experiments defining a role for FAK in mediating proliferation appear contradictory to results during development (Fig. 4), where activated FAK expression becomes markedly reduced following 10 to 12 weeks of gestation, yet extravillous cells are still highly proliferative. Based on antisense experiments using explants from placentae of 5 to 8 weeks gestation, we believe FAK's activation and mediation of proliferation and migration is a prerequisite for the very early stages of placental development $(<10$ weeks gestation). Following this period ( $>10$ weeks gestation) FAK is down-regulated, and other factors, including growth factors, must mediate proliferation and induce further differentiation of extravillous trophoblast cells toward a fully invasive phenotype. It is tempting to speculate that specific growth factors and integrins may synergize to promote extravillous trophoblast proliferation or migration during development and that FAK may mediate this synergism. TGF $\beta 3$ is a candidate signaling partner for FAK since Caniggia et al (2000b) recently reported that TGF $\beta 3$ is expressed in proliferative extravillous trophoblast cells and antisense targeting of TGF $\beta 3$ in villous explants promoted invasion.

\section{Antisense Targeting of FAK Reduces MMP2 Activity}

Media from control and antisense-treated explants was assayed for MMP2 activity by gel zymography. There was a marked decrease of MMP2 activity in media from antisense treatment groups. These results suggest that inhibiting FAK expression during early placental development not only perturbs outside:inside signaling, resulting in decreased trophoblast outgrowth and cell proliferation, but may lead to decreased inside:outside signaling that normally stimulates the activity of MMP2. MMP2 activity has been implicated in the migration of villous cytotrophoblast cells off their basement membranes in the transition toward extravillous outgrowth during early placental development (Caniggia et al, 1997a), and the lack of significant outgrowth of antisense-treated explants may be due to such low MMP2 activity.

The results of our work therefore illustrate that FAK signaling appears to regulate the integrin-dependent processes of cell motility and proliferation during early placental development (Fig. 8). Both processes are reported to be components of wound healing in vitro (Coomber and Gotlieb, 1990), and they are affected by 

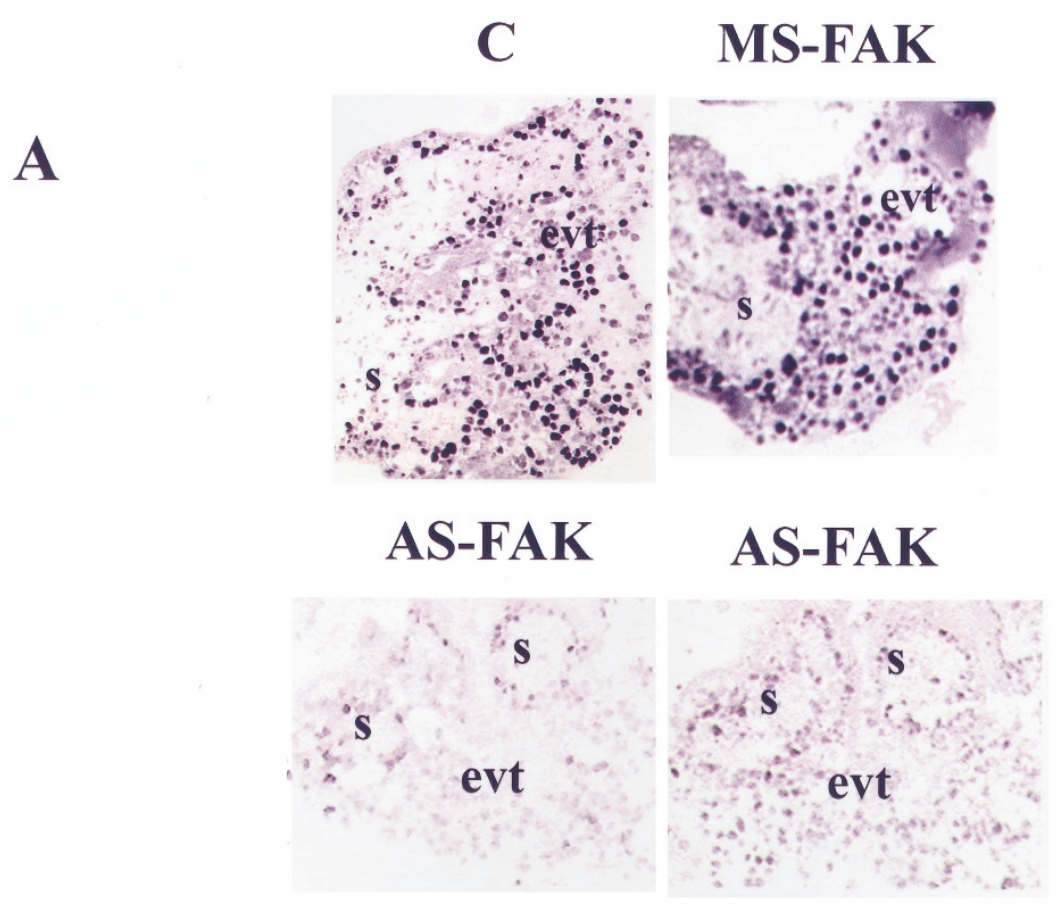

B

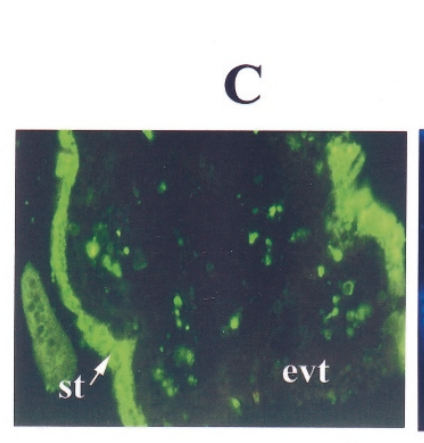

MS-FAK
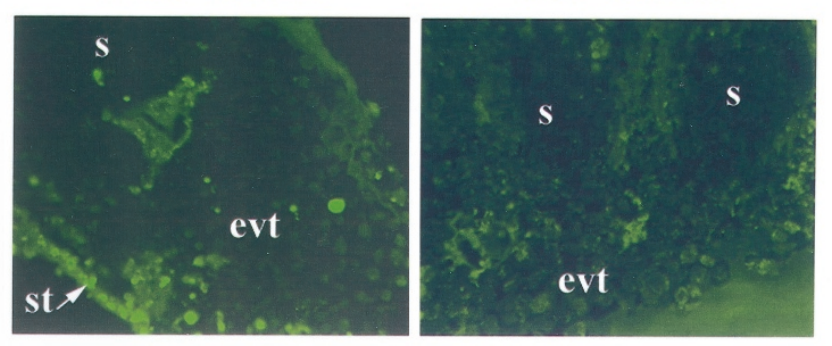

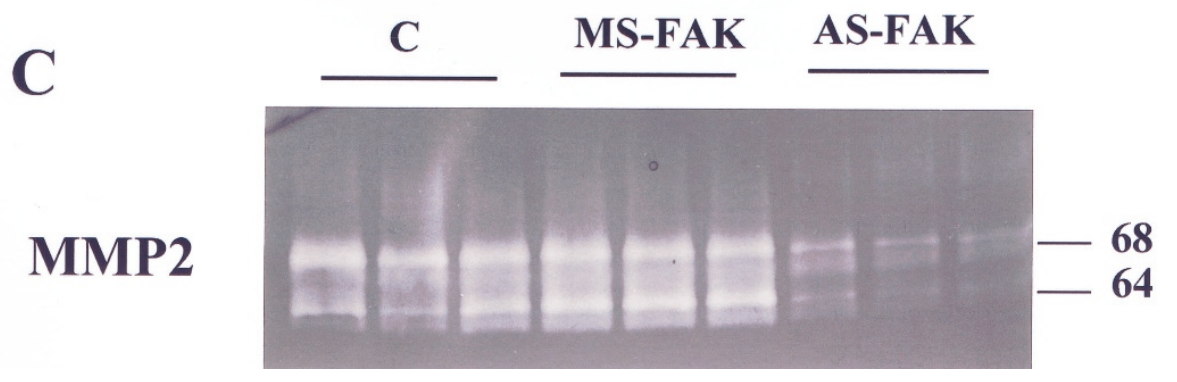

Figure 7.

Antisense targeting of FAK inhibits cell proliferation and matrix metalloproteinase-2 activity but does not lead to increased apoptosis. A, Human villous explants from antisense experiments were paraffin embedded and sectioned. Sections were used for immunocytochemistry experiments to determine the cell proliferation status (Ki67 antigen detection) of extravillous trophoblast cells. Antisense FAK (AS-FAK) treatment of explants dramatically reduced cell proliferation of extravillous 
Table 1. Effect of AS-FAK on Cell Proliferation in Extravillous Trophoblast Cell Outgrowths ${ }^{a}$

\begin{tabular}{cc}
\hline Treatment & Proliferating Cells $(\%)$ \\
\hline Control & $57 \pm 10$ \\
MS-FAK & $56 \pm 8$ \\
AS-FAK & $10 \pm 1^{\star}$ \\
\hline
\end{tabular}

AS-FAK, antisense focal adhesion kinase; MS-FAK, missense focal adhesion kinase.

${ }^{a}$ To quantitatively assess the effect of AS-FAK on cell proliferation in extravillous trophoblast cell outgrowth, we randomly counted 16 fields/slide/ experiment (3 experiments) and determined the number of Ki67-positive (proliferating) nuclei and the total number of nuclei. Data are mean \pm SEM.

${ }^{*} p<0.05$.

decreased FAK in focal adhesions (Gilmore and Romer, 1996). However, identification of the constituents of FAK signaling complexes that regulate proliferation and/or migration signals and the relative contributions of these distinct complexes toward these cellular processes is poorly understood and is an area of intense investigation. Recently, Reiske et al (2000) and Oktay et al (1999) reported that the formation of a FAK/Src complex and interaction with p130 ${ }^{\mathrm{CAS}}$ are required for the regulation of cell-cycle progression by FAK. Conversely, Xie et al (2001) have reported that FAK can associate with signal transducer and activator of transcription-1 (STAT-1) and that this signaling complex can promote cell migration. Future work is clearly required to identify the specific FAK signaling partners (including growth factors) that exist in trophoblast cells to promote proliferation and/or migration during early placental development. An understanding of the FAK signaling complexes involved in such processes may also facilitate an understanding of the etiologic basis of diseases such as preeclampsia.

\section{Materials and Methods}

\section{Villous Explant Culture}

Villous explant cultures were established from first trimester human placentae (5-8 weeks embryonic gestation) obtained from elective terminations of pregnancies by dilatation and curettage. Informed consent was obtained from the patients and all tissue samples were collected in accordance with the ethics guidelines of the University of Toronto. Villous explant cultures were established as previously described (Caniggia et al, 1997b). Small villi fragments of 20 to 40 mg wet weight were placed on Millicell-CM culture dish inserts (Millipore, Bedford, Massachusetts) precoated with Matrigel. Explants were cultured in serumfree Dulbecco's modified eagle media/nutrient mixture F12 (DMEM/F12; Gibco-BRL, Grand Island, New York) supplemented with $100 \mu \mathrm{g} / \mathrm{mL}$ streptomycin, 100 $\mathrm{U} / \mathrm{mL}$ penicillin, and $0.25 \mu \mathrm{g} / \mathrm{mL}$ ascorbic acid, $\mathrm{pH} 7.4$. Villous explants were placed at $37^{\circ} \mathrm{C}$ either in standard tissue culture conditions of $5 \% \mathrm{CO}_{2}$ in $95 \%$ air (20\% $\mathrm{O}_{2}$ environment) or maintained in an atmosphere of $3 \% \mathrm{O}_{2} / 93 \% \mathrm{~N}_{2} / 5 \% \mathrm{CO}_{2}$ (3\% $\mathrm{O}_{2}$ environment). For each experiment replicate tissue samples from the same placenta were used, and for each treatment explant cultures were set up in triplicate. The morphological integrity and viability of villous explants and their EVT outgrowth and migration were monitored daily for up to 6 days as previously reported (Caniggia et al, 1997b).

\section{Antisense Targeting with Phosphorothioate Oligonucleotides}

Phosphorothioate oligonucleotides were synthesized on a DNA synthesizer and purified by capillary electrophoresis. Oligonucleotides of 20 base pairs (bp) (20-mer) targeted against a sequence corresponding to bp 784803 (amino acids 262-268) (Whitney et al, 1993) of FAK (AS2; 5'-ATAATCCAGCTTGAACCAAG-3') were synthesized. In addition, missense oligonucleotides (MS2-5) containing five base substitutions were also synthesized (5'-ATAATCGACGTTCAAGCAAG-3'). The sequences used for these experiments have been previously documented (Xu et al, 1996). Oligonucleotides were dissolved in water and their concentration was estimated by optical density measurement at $\mathrm{OD}_{260}$. Villous explants, prepared from placentae of 5 to 8 weeks gestation, were incubated for an overnight period in DMEM/F12 alone and then incubated in DMEM/F12 alone or in medium containing antisense or missense oligonucleotides (10 $\mu \mathrm{M})$. All explants were cultured in a $3 \% \mathrm{O}_{2}$ atmosphere. Culture media, with and without oligonucleotides, was routinely changed every 48 hours. Experiments were carried out in triplicate and repeated at least three times.

\section{SDS-PAGE and Immunoblotting}

Frozen placenta samples were pulverized under liquid nitrogen with a mortar and pestle and homogenized in radioimmunoprecipitation assay (RIPA) lysis buffer (50 mм Tris- $\mathrm{HCl}, \mathrm{pH} 7.5 ; 150 \mathrm{~mm} \mathrm{NaCl} ; 1 \%$ [vol/vol] Triton $\mathrm{X}-100 ; 1 \%$ [wt/vol] sodium deoxycholate; $0.1 \%$ [wt/ vol] SDS; $100 \mu \mathrm{M} \mathrm{Na} \mathrm{VO}_{3}$; and COMPLETE, Mini EDTA-free protease inhibitors [Roche Molecular Biochemicals, Laval, Quebec, Canada]). Samples were centrifuged at $15,000 \times g$ at $4^{\circ} \mathrm{C}$ for 15 minutes, and the supernatants were collected. Protein concentrations were determined by the Bradford Assay (Bradford, 1976) using Bio-Rad protein assay dye reagent (Bio-Rad Laboratories, Mississauga, Ontario, Canada). Protein samples (100 $\mu \mathrm{g} / \mathrm{lane}$ ) were separated by

trophoblast cells (evt) compared with control $(C)$ and missense (MS-FAK) treated explants. Control panel contains neighboring sections from antisense experiments, which were only incubated with the appropriate control lgG. S, stromal cells. $(\times 100)$. B. Paraffin sections of control $(C)$, missense $(M S-F A K)$, and antisense-treated $(A S-F A K)$ human villous explants were processed for terminal deoxynucleotidyl transferase-dUTP-nick end labeling (TUNEL) assays. Extravillous trophoblast cells $(e v t)$ in both control and antisense-treated explants did not exhibit any significant positive TUNEL reaction, indicating that the observed antisense phenotype was not due to increased apoptosis. C, Culture media from antisense experiments was collected and analyzed for MMP2 activity by gel zymography. Antisense FAK treatment of explants $(A S-F A K)$ resulted in significant decreases in MMP2 activity compared with control $(C)$ and missense treatments $(M S-F A K)$. 
polyacrylamide gel electrophoresis according to the method of Laemmli (1970), using $4 \%$ to $12 \%$ gradient polyacrylamide gels (Helix Technologies, Scarborough, Ontario, Canada). All protein sample sets were checked for equal loading with Coomasie Blue staining. Protein samples were electroblotted to $0.45 \mu \mathrm{m}$ polyvinylidene difluoride membrane (Millipore Canada, Nepean, Ontario, Canada).

Unless otherwise stated, all incubations were done at room temperature and with constant agitation. Blots were blocked in 5\% (wt/vol) skim milk powder for 1 hour (5\% [wt/vol] bovine serum albumin for detection of phosphotyrosines), rinsed $1 \times 15$ minutes in Tris-buffered saline (20 mm Tris base, $137 \mathrm{~mm} \mathrm{NaCl}$, $\mathrm{pH} 7.6$ ) with $0.1 \%$ (vol/vol) Tween-20 (TBST) and $2 \times$ 5 minutes in TBST. Primary antisera were diluted in blocking solution and incubated with blots for 1 hour or overnight at $4^{\circ} \mathrm{C}$. Membranes were rinsed $1 \times 15$ minutes in TBST, followed by two more washes for 5 minutes in TBST. Appropriate secondary antisera, conjugated to horseradish peroxidase (Amersham Pharmacia Biotech, Baie d'Urfe, Quebec, Canada), were also diluted in blocking solution and incubated with membranes for 1 hour. Membranes were washed $1 \times 15$ minutes in TBST then $4 \times 5$ minutes in TBST. Proteins were detected using the Amersham Pharmacia Biotech ECL detection system and multiple exposures were generated to ensure the linearity of the film response.

For immunoblot analysis, rabbit polyclonal antisera raised against FAK (C-903) and phosphotyrosines (PY99) were purchased from Santa Cruz Biotechnology (Santa Cruz, California). FAK-specific antisera were used at 1:1000 dilution, and PY99 was used at a dilution of $1: 2500$.

\section{Immunoprecipitations}

Five hundred-microgram protein samples were diluted in RIPA buffer to a concentration of $1 \mu \mathrm{g} / \mu \mathrm{L}$ and then precleared with $20 \mu \mathrm{L}$ of Protein-A Sepharose 4B (Zymed Laboratories, Markham, Ontario, Canada) for 30 minutes at $4^{\circ} \mathrm{C}$ on a nutator. Samples were centrifuged at $1500 \mathrm{rpm}$ at $4^{\circ} \mathrm{C}$ for 1 minute, the supernatants were retained on ice, and the pellet was discarded. One microgram of antisera was added to each sample, and the mixtures were incubated at $4^{\circ} \mathrm{C}$ on a nutator overnight. Twenty microliters of Protein-A Sepharose 4B was added to each lysate and incubated at $4^{\circ} \mathrm{C}$ for 1 hour or overnight on a rotator. Precipitates were collected by centrifugation at 2500 rpm for 5 minutes, and supernatants were collected and discarded. The Sepharose 4B pellets were washed four times with $0.5 \mathrm{~mL}$ of RIPA buffer with repeated centrifugations at $2500 \mathrm{rpm}$. The final pellets were resuspended in $\times 1$ SDS loading buffer, boiled for 3 minutes, centrifuged, and analyzed by polyacrylamide gel electrophoresis and western blotting.

\section{Immunocytochemistry}

Placental tissue of 4 to 15 weeks of gestation and villous explants of 5 to 8 weeks of gestation were fixed in $4 \%$ (wt/vol) paraformaldehyde in PBS overnight at $4^{\circ} \mathrm{C}$ with constant agitation. Tissues were rinsed with two washes of cold PBS and then dehydrated for 1

\section{Early Placental Development Requires FAK Signalling}
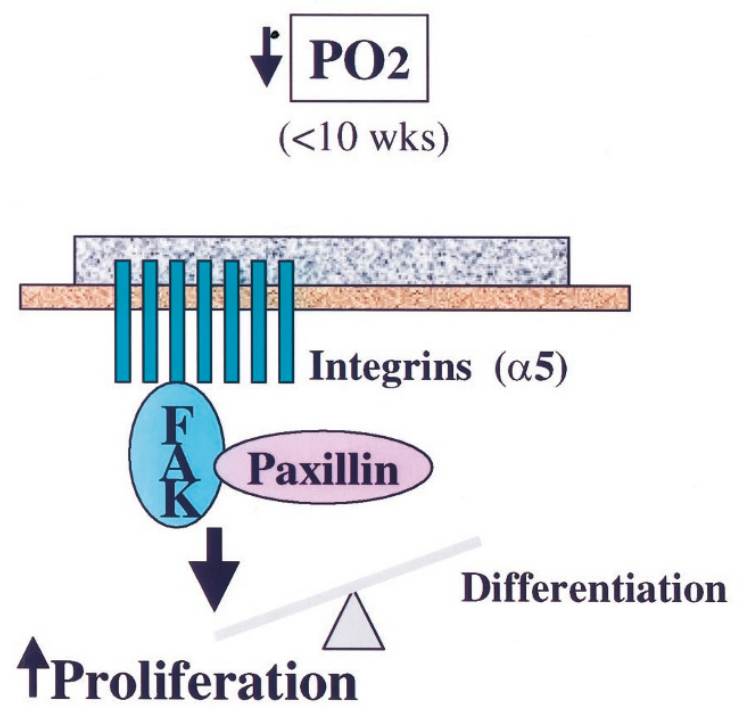
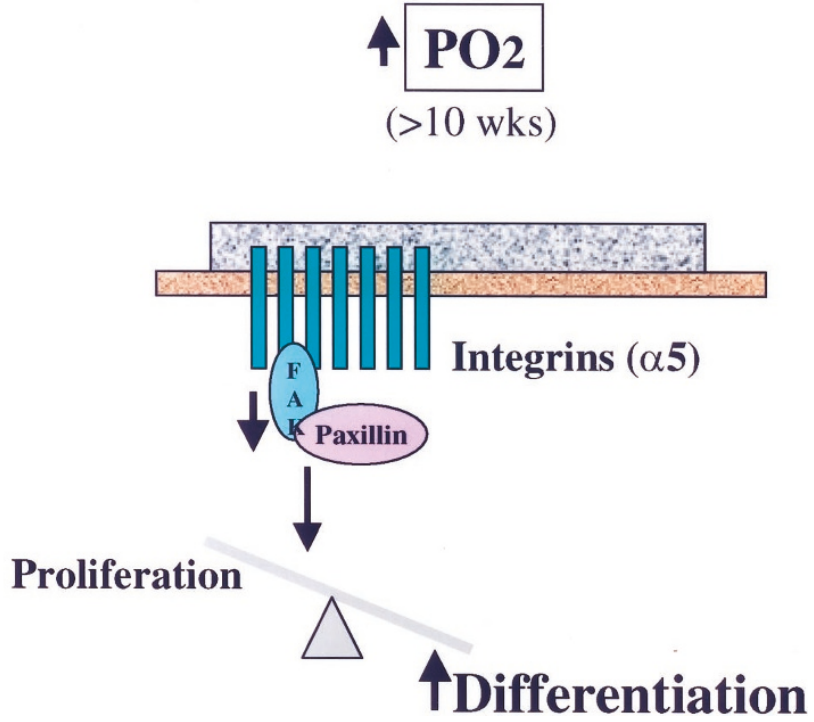

Figure 8.

A model for FAK as a key mediator of trophoblast differentiation. During early human placental development, when $\mathrm{pO}_{2}$ levels in the intervillous space are low, FAK expression and activity are positively regulated. Active FAK is localized to a transitional zone of extravillous trophoblast cells that are proliferative and migratory but not yet fully differentiated into an invasive phenotype. FAK is essential for shifting the balance between proliferation and differentiation (into an invasive phenotype) to favor proliferation during early placental differentiation. Upon exposure of trophoblast cells to higher $\mathrm{pO}_{2}$ levels, $\mathrm{FAK}$ expression and activity decrease, and $\mathrm{FAK}$ 's mediation of signaling pathways is reduced so that differentiation of extravillous trophoblast cells toward an invasive pathway becomes favored. 
hour each through a graded ethanol series $(70 \%$, $80 \%, 90 \%, 95 \%, 100 \%)$. Samples were cleared in xylene for 1 hour and then infiltrated in paraffin overnight at $60^{\circ} \mathrm{C}$. Tissues were then placed in moulds containing fresh paraffin before cooling.

Immunofluorescence Detection. Five-micrometerthick paraffin sections of placental tissue and villous explants were placed on SUPERFROST Plus (Fisher Scientific Ltd., Nepean, Ontario, Canada) slides and dried at $37^{\circ} \mathrm{C}$ overnight. Sections were dewaxed in xylene, rehydrated in descending grades of ethanol, and finally soaked in PBS. Tissues were permeabilized in $0.125 \%$ (wt/vol) trypsin in PBS for 10 minutes at room temperature and rinsed in PBS. Sections were blocked in $5 \%$ (vol/vol) normal goat serum/1\% (wt/vol) bovine serum albumin for 30 minutes at room temperature. Upon addition of appropriate primary antisera, sections were incubated overnight at $4^{\circ} \mathrm{C}$. Tissue sections were rinsed in PBS and incubated for 1 hour at room temperature on a shaker with the appropriate fluorescently conjugated secondary antisera. Tissues were washed in cold PBS containing $0.02 \%$ (vol/ $/ \mathrm{vol}$ ) Tween-20 and mounted in DAKO mounting media (DAKO Diagnostics, Mississauga, Ontario, Canada) before observation on a Bio-Rad MRC-600 laser scanning confocal microscope (Department of Pathology, Mt. Sinai Hospital, Toronto, Ontario, Canada).

For immunofluorescence experiments, a rabbit polyclonal antisera raised against FAK (C-20) was purchased from Santa Cruz Biotechnology and a rabbit polyclonal antisera raised against active FAK, phosphorylated on Tyr-397, was obtained from MediCorp Incorporated (Montreal, Quebec, Canada). Mouse monoclonal antisera raised against paxillin was purchased from Transduction Laboratories (BDPharMingen, Mississauga, Ontario, Canada). Monoclonal antisera specific for $\alpha 5$ integrin was purchased from Chemicon International (Temecula, California). FITC-conjugated goat anti-mouse IgG was purchased from Zymed Laboratories and Texas Red-conjugated goat anti-rabbit IgG was purchased from Vector Laboratories (Burlington, Ontario, Canada).

Immunoperoxidase-Based Detection. Experiments were performed according to Caniggia et al (2000a). Five-micrometer-thick paraffin sections of villous explants were dewaxed, and endogenous peroxidase enzyme activity was quenched with $1.5 \%$ ( $\mathrm{vol} / \mathrm{vol})$ hydrogen peroxide in methanol for 30 minutes. Antigen was retrieved by incubation with $0.125 \%$ (wt/vol) trypsin in PBS for 10 minutes at room temperature. Nonspecific binding sites were blocked using 5\% (vol/vol) normal goat serum and 1\% (wt/vol) bovine serum albumin in Tris buffer for 30 minutes at room temperature. Primary antibody was applied overnight at $4^{\circ} \mathrm{C}$. Sections were washed three times with Tris buffer, $\mathrm{pH} 7.6$, incubated with biotinylated secondary antibody for 1 hour at room temperature, and then washed three times in Tris buffer. Slides were incubated for 1 hour with an avidin-biotin complex and subsequently washed in Tris buffer. Slides were developed in $0.075 \%$ (wt/vol) 3,3-diaminobenzidine in Tris buffer containing $0.002 \%$ (vol/vol) hydrogen per- oxide, giving rise to a brown product. After light counterstaining with toluidine blue, slides were dehydrated in an ascending ethanol series and then cleared in xylene and mounted.

For immunocytochemistry experiments using immunoperoxidase detection, purified mouse monoclonal antisera raised against human Ki67 was purchased from Roche Molecular Biochemicals and used at 1:20 dilution. Matrix metalloproteinase-2 (MMP2)-specific monoclonal antisera was purchased from Ontogeny Research Products (Calbiochem, Cambridge, Massachusetts) and used at 1:40 dilution.

\section{TUNEL Assay}

An in situ cell death detection kit was purchased from Roche Molecular Biochemicals and TUNEL assays were performed according to instructions provided by the manufacturer. Paraffin sections of tissue were dewaxed in xylene, rehydrated in descending grades of ethanol, and finally soaked in PBS. Tissue sections were pretreated with Proteinase $\mathrm{K}(20 \mu \mathrm{g} / \mathrm{ml})$ in TrisEDTA buffer ( $50 \mathrm{~mm}$ Tris, $5 \mathrm{~mm}$ EDTA, pH 8) for 15 minutes at $37^{\circ} \mathrm{C}$ before treatment with TUNEL labeling mixture. Images were captured with a LEICA DC 200 imager (Leica, Wetzlar, Germany).

\section{Zymography}

Metalloproteinase detection was carried out as previously described (Caniggia et al, 1997a). Briefly, conditioned media were collected from antisense-FAK and control explants following termination of the experiments. Two microlitres of media were mixed with $10 \%$ (vol $/ \mathrm{vol}$ ) glycerol, 2\% (wt/vol) SDS, $0.0025 \%$ (wt/vol) bromophenol blue, $0.5 \mathrm{M}$ Tris, $\mathrm{pH} 6.8$, and subjected to substrate-gel electrophoresis on a $10 \%$ polyacrylamide gel $(\mathrm{wt} / \mathrm{vol})$ impregnated with $0.1 \%$ gelatin (Helix Technologies). After electrophoresis, gels were washed in $2.5 \%$ ( $\mathrm{vol} / \mathrm{vol}$ ) Triton X-100 washes $(2 \times 30$ minutes at room temperature) to remove SDS, then equilibrated with developing buffer (50 mm Tris-HCL, $0.2 \mathrm{M} \mathrm{NaCl}, 5 \mathrm{~mm} \mathrm{CaCl}$, Brij 35, pH 7.2) for 30 minutes, and incubated overnight in the same buffer at $37^{\circ} \mathrm{C}$. Gels were stained with $0.1 \%$ (wt/vol) Coomassie brilliant blue G-250 and destained to visualize metalloproteinase activity.

\section{Acknowledgements}

We thank Mrs. Christine Botsford and Dr. Ljiljana Petkovic for providing the placental samples. We also thank Dr. Knox Ritchie for constant encouragement and support. This work was supported by the Department of Obstetrics and Gynecology and the Canadian Institute for Health Research.

\section{References}

Bischof $\mathrm{P}$, Redard M, Gindre $\mathrm{P}$, Vassilakos $\mathrm{P}$, and Campana A (1993). Localisation of alpha2, alpha5 and alpha6 integrin subunits in human endometrium, decidua and trophoblast. Eur J Obstet Gynecol Reprod Biol 51:217-226. 
Boudreau NJ and Jones PL (1999). Extracellular matrix and integrin signaling: The shape of things to come. Biochem $\mathrm{J}$ 339:481-488.

Bradford MM (1976). A rapid and sensitive method for the quantification of microgram quantities of protein utilizing the principle of protein-dye binding. Anal Biochem 72:248-254.

Burton GJ, Jauniaux E, and Watson AL (1999). Maternal arterial connections to the placental intervillous space during the first trimester of human pregnancy: The Boyd Collection revisited. Am J Obstet Gynecol 181:718-724.

Caniggia I, Lye SJ, and Cross JC (1997a). Activin is a local regulator of human cytotrophoblast cell differentiation. Endocrinology 138:3976-3986.

Caniggia I, Mostachfi H, Winter J, Gassmann M, Lye SJ, Kuliszewski M, and Post M (2000a). Hypoxia-inducible factor-1 mediates the biological effects of oxygen on human trophoblast differentiation through TGF $\beta 3$. J Clin Invest 105: 577-587.

Caniggia I, Taylor CV, Ritchie JWK, Lye SJ, and Letarte M (1997b). Endoglin regulates trophoblast differentiation along the invasive pathway in human placental villous explants. Endocrinology 138:4977-4988.

Caniggia I, Winter J, Lye SJ, and Post M (2000b). Oxygen and placental development during the first trimester: Implications for the pathophysiology of pre-eclampsia. Placenta 21(Suppl A):S25-S30.

Cary L, Chang J, and Guan J (1996). Stimulation of cell migration by overexpression of focal adhesion kinase and its association with src and fyn. J Cell Sci 109:1787-1794.

Coomber BL and Gotlieb AI (1990). In vitro endothelial wound repair: Interaction of cell migration and proliferation. Arteriosclerosis 10:215-222.

Cross JC, Werb Z, and Fisher SJ (1994). Implantation and the placenta: Key pieces of the developmental puzzle. Science 266:1508-1518.

Damsky CH, Fitzgerald ML, and Fisher SJ (1992). Distribution patterns of extracellular matrix components and adhesion receptors are intricately modulated during first trimester cytotrophoblast differentiation along the invasive pathway in vivo. J Clin Invest 89:210-222.

Damsky CH, Librach CL, Lim KH, Fitzgerald ML, McMaster MT, Janatpour M, Zhou Y, Logan SK, and Fisher SJ (1994). Integrin switching regulates normal trophoblast invasion. Development 120:3657-3666.

Frisch SM, Vuori K, Ruoslahti E, and Chan-Hui, P-Y (1996). Control adhesion dependent cell survival by focal adhesion kinase. J Cell Biol 134:793-799.

Genbacev O, Joslin R, Damsky CH, Polliotti BM, and Fisher SJ (1996). Hypoxia alters early gestation human cytotrophoblast differentiation/invasion in vitro and models the placental defects that occur in preeclampsia. J Clin Invest 97:540-550.

Genbacev O, Zhou Y, Ludlow JW, and Fisher SJ (1997). Regulation of human placental development by oxygen tension. Science 277:1669-1672.

Gilmore AP and Romer LH (1996). Inhibition of focal adhesion kinase (FAK) signalling in focal adhesions decreases cell motility and proliferation. Mol Biol Cell 7:1209-1224.

Hanks SK and Polte TR (1997). Signaling through focal adhesion kinase. Bioessays 19:137-145.
Hungerford JE, Comptom MT, Matter ML, Hoffstrom BG, and Otey CA (1996). Inhibition of pp125FAK in cultured fibroblasts results in apoptosis. J Cell Biol 135:1393-1390.

Ilic D, Furuta Y, Kanazawa S, Takeda N, Sobue K, Nakatsuji N, Nomura S, Fujimoto J, Okada M, and Yamamoto T (1995). Reduced cell motility and enhanced focal adhesion contact formation in cells from FAK-deficient mice. Nature 377:539544.

Jauniaux E, Watson AL, Hempstock J, Bao, Y-P, Skepper $\mathrm{JN}$, and Burton GJ (2000). Onset of maternal arterial blood flow and placental oxidative stress: A possible factor in human early pregnancy failure. Am J Pathol 157:3251-3262.

Juliano R (1996). Cooperation between soluble factors and integrin-mediated cell anchorage in the control of cell growth and differentiation. Bioessays 18:911-917.

Laemmli UK (1970). Cleavage of structural proteins during the assembly of the head of the bacteriophage T4. Nature 227:680-685.

Librach CL, Werb Z, Fitzgerald ML, Chiu K, Corwin NM, Esteves RA, Grobelny D, Galardy R, Damsky CH, and Fisher SJ (1991). 92 kD Type IV collagenase mediates invasion of human cytotrophoblasts. J Cell Biol 113:437-449.

Liu S, Thomas SM, Woodside DG, Rose DM, Kiosses WB, Pfaff M, and Ginsberg MH (1999). Binding of paxillin to $\alpha 4$ integrins modifies integrin-dependent biological responses. Nature 402:676-681.

MacPhee DJ and Lye SJ (2000). Focal adhesion signaling in the rat myometrium is abruptly terminated with the onset of labour. Endocrinology 141:274-283.

Oktay M, Wary, KK., Dans M, Birge RB, and Giancotti FG (1999). Integrin-mediated activation of focal adhesion kinase is required for signaling to Jun $\mathrm{NH}_{2}$-terminal kinase and progression through the G1 phase of the cell cycle. J Cell Biol 145:1461-1469.

Owen JD, Ruest PJ, Fry DW, and Hanks SK (1999). Induced focal adhesion kinase (FAK) expression in FAK-null cells enhances cell spreading and migration requiring both autoand activation loop phosphorylation sites and inhibits adhesion-dependent tyrosine phosphorylation of Pyk2. Mol Cell Biol 19:4806-4818.

Parast MM, Aeder S, and Sutherland AE (2001). Trophoblast giant-cell differentiation involves changes in cytoskeleton and cell motility. Dev Biol 230:43-60.

Parsons JT, Martin KH, Slack JK, Taylor JM, and Weed SA (2000). Focal adhesion kinase: A regulator of focal adhesion dynamics and cell movement. Oncogene 19:5606-5613.

Reiske HR, Zhao J, Han DC, Cooper LA, and Guan, J-L (2000). Analysis of FAK-associated signaling pathways in the regulation of cell cycle progression. FEBS Lett 486:275-280.

Richardson A, Malik RK, Hildebrand JD, and Parsons JT (1997). Inhibition of cell spreading by expression of the C-terminal domain of focal adhesion kinase (FAK) is rescued by coexpression of Src or catalyticaly inactive FAK: A role for paxillin tyrosine phosphorylation. Mol Cell Biol 17:6906-6914.

Richardson A and Parsons JT (1995). Signal transduction through integrins: A central role for focal adhesion kinase? Bioessays 17:229-236.

Rodesch F, Simon P, Donner C, and Jauniaux E (1992). Oxygen measurements in endometrial and trophoblastic tissues during early pregnancy. Obstet Gynecol 80:283-285. 
Ruest PJ, Roy S, Shi E, Mernaugh RL, and Hanks SK (2000). Phosphospecific antibodies reveal focal adhesion kinase activation loop phosphorylation in nascent and mature focal adhesions and requirement for the autophosphorylation site. Cell Growth Differ 11:41-48.

Ruoslahti E and Reed JC (1994). Anchorage dependence, integrins, and apoptosis. Cell 77:477-478.

Schlaepfer DD, Hauck CR, and Sieg DJ (1999). Signaling through focal adhesion kinase. Prog Biophys Mol Biol 71:435-478.

Schlaepfer DD and Hunter T (1998). Integrin signalling and tyrosine phosphorylation: Just the FAKs? Trends Cell Biol 8:151-157.

Seko Y, Takahashi N, Sabe H, Tobe K, Kadowaki T, and Nagai $R$ (1999). Hypoxia induces activation and subcellular translocation of focal adhesion kinase $\left(\mathrm{p} 125^{\mathrm{FAK}}\right)$ in cultured rat cardiac myocytes. Biochem Biophys Res Comm 262: 290-296.

Taylor JM, Mack CP, Nolan K, Regan CP, Owens GK, and Parsons JT (2001). Selective expression of an endogenous inhibitor of FAK regulates proliferation and migration of vascular smooth muscle cells. Mol Cell Biol 21:1565-1572.

Tsukuda T, Tomooka Y, Takai S, Ueda Y, Nishikawa S, Yagi T, Tokunaga T, Takeda N, Suda Y, and Abe S (1993). Enhanced proliferative potential in culture of cells from p53deficient mice. Oncogene 8:3312-3322.
Wang GL, Jiang BH, Rueand EA, and Semenza GL (1995). Hypoxia inducible factor 1 is a basic helix-loop-helix PAS heterodimer regulated by cellular $\mathrm{O}_{2}$ tension. Proc Natl Acad Sci USA 92:5510-5514.

Whitney GS, Chan, P-Y, Blake J, Cosand WL, Neubauer MG, Aruffo A, and Kanner SB (1993). Human T and B lymphocytes express a structurally conserved focal adhesion kinase, pp125 ${ }^{\mathrm{FAK}}$. DNA Cell Biol 12:823-830.

Xie B, Zhao J, Kitagawa M, Durbin J, Madri JA, Guan J-L, and Fu X-Y (2001). Focal adhesion kinase activates STAT1 in integrin-mediated cell migration and adhesion. J Biol Chem 276:19512-19523.

Xu, L-H, Owens LV, Sturge GC, Yang X, Liu ET, Craven RJ, and Cance WG (1996). Attenuation of the expression of the focal adhesion kinase induces apoptosis in tumour cells. Cell Growth Diff 7:413-418.

Zhao J-H, Reiske H, and Guan J-L (1998). Regulation of the cell cycle by focal adhesion kinase. J Cell Biol 143:19972008. 